\title{
Kinetic of Forced Oxidation of Grape Seeds, Walnuts and Corn Germs Oils in the Presence of Antioxidants
}

\author{
Iurie Subotin, Raisa Druta, Violina Popovici, Ecaterina Covaci, Rodica Sturza* \\ Technical University of Moldova, Chisinau, Republic of Moldova \\ Email: *rodica.sturza@chim.utm.md
}

How to cite this paper: Subotin, I., Druta, R., Popovici, V., Covaci, E. and Sturza, R. (2021) Kinetic of Forced Oxidation of Grape Seeds, Walnuts and Corn Germs Oils in the Presence of Antioxidants. Food and Nutrition Sciences, 12, 1326-1339. https://doi.org/10.4236/fns.2021.1212097

Received: October 30, 2021

Accepted: December 24, 2021

Published: December 27, 2021

Copyright $\odot 2021$ by author(s) and Scientific Research Publishing Inc. This work is licensed under the Creative Commons Attribution International License (CC BY 4.0).

http://creativecommons.org/licenses/by/4.0/ (c) (i) Open Access

\begin{abstract}
The present study aimed to investigate the effectiveness of the use of some antioxidants- $\alpha$-tocopherol, n-octyl gallate, L-ascorbic acid 6-palmitate and matcha extract (green tea) as inhibitors of grape seeds, walnuts and corn germ oils oxidation. The oxidation was studied in a forced regime during 700 $\mathrm{h}$, by the addition of hydrogen peroxide and $\mathrm{Cu}^{2+}$ ions. The optimal conditions of the accelerated oxidation process in the analysed systems were established. The progress of lipid oxidation was evaluated by measuring the peroxide value $(\mathrm{PV})$ and conjugated dienes and trienes $(\mathrm{CD}, \mathrm{CT})$. A series of secondary products of the lipid oxidation were identified: hexanal, octanal and hydroxy-nonadienal. The intensity of the formation of these compounds during oxidation was monitored. The results of this study showed that the oil samples with the addition of antioxidants showed considerably lower oxidation values compared to the control sample. More effective was the action of L-ascorbic acid 6-palmitate and n-octyl gallate, the optimum concentration was $0.1 \%$. An inhibitory effect of the oxidation process was noted for $\alpha$ tocopherol and matcha extract, the optimal addition concentration was $1 \%$.
\end{abstract}

\section{Keywords}

Lipids, Accelerated Oxidation, Inhibition, Antioxidants, Oils

\section{Introduction}

Lipid oxidation is one of the major causes of decreased nutritional value of foods, limiting their shelf life. This phenomenon leads to changes in the nutritional and organoleptic quality of the oils [1] [2]. Consumption of metabolites of oxidative degradation of lipids is the cause of oxidative stress in the human body 
and, respectively, causes multiple morbid conditions for human health [3]. The oxidative stability of oils is the resistance to oxidation during processing and storage [4] [5]. Oxidation resistance can be expressed as the time required to reach the critical oxidation point, whether it is a sensory change or a sudden acceleration of the oxidative process [6]. Oxidative stability is an important indicator to determine oil quality and shelf life because low molecular weight compounds are produced during oxidation.

The rates of synthesis of peroxide lipid radical and hydroperoxide depend only on oxygen availability and temperature [7]. When radicals react with each other, non-radical species occur and the reaction stops. The primary products of lipid oxidation including hydroperoxides are relatively stable at room temperature and in the absence of metals. However, in the presence of metals or at high temperatures, they are easily decomposed into alkoxy radicals and then form aldehydes, ketones, acids, esters, alcohols and short chain hydrocarbons [8].

The oxidation of lipids is a process consisting of a series of stages, being influenced by the chemical structure of unsaturated fatty acids, their physical state (liquid or solid), the presence of inorganic oxidants (ions of some metals: $\left(\mathrm{Fe}^{2+}\right.$, $\mathrm{Cu}^{2+}, \mathrm{Co}^{2+}, \mathrm{Mn}^{2+}$ ) or organic (hemoglobin, myoglobin), pre-existence of free radicals, existence of lipases, quantity and quality of substances with an antioxidant role in processing, packaging and storage conditions of food products [9].

Additionally, lipid oxidation depends on the environment and initiators involved in it and can be classified into enzymatic oxidation, photooxidation and self-oxidation [10]. Enzymatic oxidation is catalyzed by lipoxygenase, cyclooxygenase and peroxidase, which catalyze the addition of oxygen to the polyunsaturated hydrocarbon chain and lead to the formation of peroxides and hydroperoxides. In particular, oils obtained by cold pressing are subjected to this type of oxidation [11]. Photooxidation is promoted mainly by ultraviolet (UV) radiation in the presence of photosensitizers/chromophores (chlorophyll, myoglobin, riboflavin and others), which absorb light and initiate a chain of photochemical reactions. Photooxidation occurs through two main mechanisms: direct photolysis and reaction with reactive oxygen species produced by photosensitizers [12]. Self-oxidation of lipids is recognized as the main oxidation mechanism in oils and fats. Inhibition of the lipid self-oxidation process is of practical importance for various industrial applications, especially for the food industry [13]. One of the most rational methods of inhibiting lipid self-oxidation is the use of affordable, relatively inexpensive natural antioxidants that do not affect the health of potential consumers [14] [15].

In order to study and select antioxidants potentially useful for inhibiting the oxidative process, it was necessary to study and understand the mechanism and kinetics of the lipid self-oxidation process, the influence of various factors The kinetic process, both in the absence and in presence of antioxidants. Grape seed, walnut and corn germ crude oils were used as substrates.

Grape seed oil is rich in phenolic compounds (especially resveratrol, quercetin, procyanidins), carotenoids, phytosterols, and polyunsaturated fatty acids 
(about $85 \%-90 \%$ ). Due to the high content of Vitamin E (ranging from 1 to 53 mg per $100 \mathrm{~g}$ of oil), it is recommended as edible oil, with beneficial properties for health, such as anti-inflammatory, cardioprotective, antimicrobial and anticancer activity [16] [17]. Walnut oil is of interest for fresh consumption, being particularly rich in polyphenolic compounds and unsaturated fatty acids: linoleic (about 64\% - 65\%) and linolenic (about 9\% - 11\%) [18] [19]. Corn oil contains $13 \%-17 \%$ of saturated fatty acids and almost no linolenic acid. Its main fatty acid is linoleic acid about $55 \%-62 \%$, followed by oleic acid at $22 \%$ $28 \%[20]$.

A prooxidant (hydrogen peroxide) and a catalyst $\left(\mathrm{Cu}^{2+}\right)$ were used to model the lipid oxidation kinetics, which initiates the singlet oxygen formation procedure [21]. Hydroxyperoxides formed in the propagation phase are the primary products of fat oxidation. Reactive oxygen species (ROS) include superoxide anion, singlet oxygen $\left({ }^{1} \mathrm{O}_{2}\right)$, lipid peroxides and hydroxyl radical:

$$
\begin{gathered}
\mathrm{Cu}^{2+}+\mathrm{RH} \rightarrow \mathrm{Cu}^{+}+\mathrm{R}^{-}+\mathrm{H}^{+} \\
\mathrm{Cu}^{+}+{ }^{3} \mathrm{O}_{2} \rightarrow \mathrm{Cu}^{2+}+\mathrm{O}_{2}^{-} \cdot \\
\mathrm{O}_{2}^{-}+\mathrm{O}_{2}^{-} \cdot+2 \mathrm{H}^{+} \rightarrow{ }^{1} \mathrm{O}_{2}+\mathrm{H}_{2} \mathrm{O}_{2} \\
\mathrm{H}_{2} \mathrm{O}_{2}+\mathrm{O}_{2}^{-} \rightarrow \mathrm{HO} \cdot+\mathrm{OH}^{-}+{ }^{1} \mathrm{O}_{2} \\
\mathrm{Cu}^{+}+\mathrm{H}_{2} \mathrm{O}_{2} \rightarrow \mathrm{Cu}^{2+}+\mathrm{OH}^{-}+\mathrm{HO} .
\end{gathered}
$$

Metals ions also accelerate the self-oxidation of the oil by the breakdown of hydroperoxides [22]:

$$
\begin{aligned}
& \mathrm{ROOH}+\mathrm{Cu}^{+} \rightarrow \mathrm{RO} \cdot+\mathrm{Cu}^{2+}+\mathrm{OH}^{-} \\
& \mathrm{ROOH}+\mathrm{Cu}^{2+} \rightarrow \mathrm{ROO} \cdot+\mathrm{Cu}^{+}+\mathrm{H}^{+} .
\end{aligned}
$$

Antioxidants convert ROS into different non-radical species, break the chain self-oxidation reaction initiated by ROS and lower localized oxygen concentrations.

There are many compounds capable of inhibiting oxidation, but only some are allowed for human consumption due to safety concerns. High doses of synthetic antioxidants can cause DNA damage. BHA and BHT have been shown to be responsible for adverse effects on the liver and carcinogenesis in animal studies [23]. In addition, very little is known about the appearance and fate of these compounds in the environment [24]. The tendency to replace these antioxidants with natural ones has increased over the last years. But some natural antioxidants have lower antioxidant activity than their synthetic counterparts, which means using them in larger quantities. However, natural antioxidants are a valuable alternative to synthetic ones, provided they are used within regulatory limits.

The paper carried out a study on the process of forced oxidation of oils from grape seeds, walnut kernels and corn germs in the presence of hydrogen peroxide and $\mathrm{Cu}$ (II) ions. The action of some antioxidants ( $\alpha$-tocopherol, n-octyl gallate, L-ascorbic acid 6-palmitate and matcha extract (green tea)) on the oxida- 
tion process of the analyzed oils was investigated.

\section{Materials and Methods}

The purpose of the work was to study unrefined local oils from grape seeds, walnut and maize germ, obtained by cold pressing. Chemical reagents with a degree of analytical purity were used for investigations. The following antioxidants (commercial products) were used to inhibit the oxidation of oils: a-tocopherol, n-octyl gallate, L-ascorbic acid 6-palmitate and matcha extract (green tea) (Figure 1).

The samples of the investigated oils with a mass of $50 \mathrm{~g}$ each, additionally containing different concentrations of $\mathrm{H}_{2} \mathrm{O}_{2}$ and $\mathrm{Cu}^{2+}$, were placed in hermetically sealed vessels. Periodically, for 700 hours, samples with a mass of 1 gr were extracted for the investigation of lipid oxidation (Figure 2).

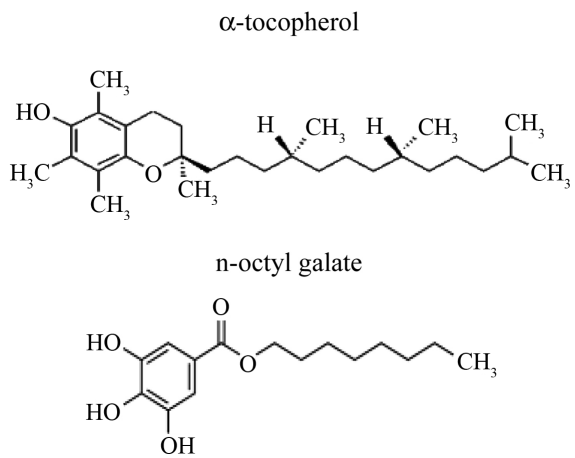

L-ascorbic acid 6-palmitate<smiles>CCCCC(=O)OC[C@@H](O)[C@H]1OC(=O)C(O)=C1O</smiles>

matcha extract

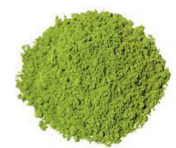

Figure 1. Antioxidants used for inhibition of peroxidation process.

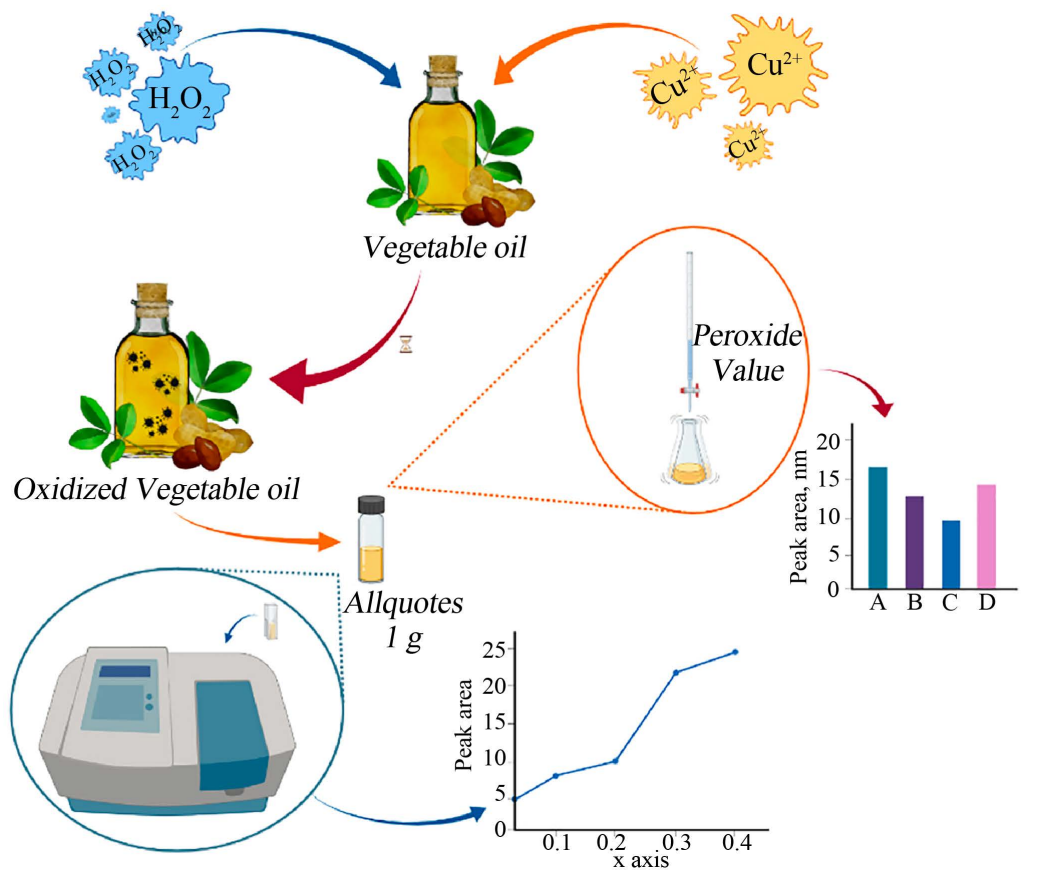

Figure 2. Scheme of the oils oxidation process used in the experiment (created by author using BioRender App). 
Peroxide value (PV) determination. For the PV determination, the standard method ISO 3960 (2017) was used. This is an iodometric titration, based on the oxidation of the iodide ion by hydroperoxides [25]. The control experiment (without oil sample) was performed at the end of each determination. PV was expressed in millimol of active oxygen per $\mathrm{kg}$ of oil $(\mathrm{mmol} / \mathrm{kg})$ and was calculated by the following equation:

$$
\mathrm{PV}=\frac{\left(V_{1}-V_{2}\right) \cdot N_{\text {tios }} \cdot 1000}{m},[\mathrm{mmol} / \mathrm{kg}]
$$

where:

$V_{1}$ : volume $0.01 \mathrm{~N}$ sodium thiosulfate solution consumed for titration of the test sample, $\mathrm{cm}^{3}$;

$V_{2}$ : volume of $0.01 \mathrm{~N}$ sodium thiosulfate solution used for titration in the control;

experiment, $\mathrm{cm}^{3}$;

$m$ : mass of the analysed sample, g;

$N_{\text {tios: }}$ : the normality of sodium thiosulfate solution $(0.01 \mathrm{~N})$.

Conjugated dienes (CD) and conjugated trienes (CT) determination. At the initial stages of the autocatalytic radical oxidation of lipids, the position of the double bonds of unsaturated fatty acids changes [26]. These changes can be investigated by the spectrophotometric method, measuring the absorbance at 232 and $270 \mathrm{~nm}$, thus monitoring the formation of conjugated dienes and trienes in polyunsaturated fatty acids [27].

For quantification of the ratio of conjugated dienes and trienes of weighed $0.01 \mathrm{~g}$ of sample were analyzed and transferred to a $25 \mathrm{ml}$ volumetric flask. Hexane was added to the volumetric flask up to the graduation mark and the resulting solution was thoroughly stirred.

The absorbance of the solution at 232 and $270 \mathrm{~nm}$ was determined using a 10 $\times 10 \mathrm{~mm}$ quartz cuvette. The ratio of conjugated dienes and trienes was calculated according to the following equations:

$$
\begin{gathered}
C_{\mathrm{CD} / \mathrm{CT}}=A_{232} / A_{270} /(e \times l)[\mathrm{mmol} / \mathrm{L}] ; \\
\mathrm{CD} / \mathrm{CT}=\left(C_{\mathrm{CD} / \mathrm{CT}} \times 2.5 \times 10^{4}\right) / w,
\end{gathered}
$$

where:

$C_{\mathrm{CD} / \mathrm{CT}}$ : diene / triene concentration;

$w$. mass of the analyzed sample, gr;

I: length of the optical path, cm;

$A_{232} / A_{270}$ : optical density ratio;

$e$ : the molar absorption coefficient of linoleic hydropyroxide.

The measurements were performed using a HACH LANGE DR 5000 spectrophotometer, in a quartz cuvette $(10 \times 10 \mathrm{~mm})$. All measurements were performed in triplicate.

The quality indices of the oils were determined by standard methods of analysis [28]. 
Dosage of volatile compounds of lipid oxidation. The determination of volatile lipid oxidation compounds was performed by the GC/MS method, using the Shimadzu GCMS-QP2010 Plus system. The three-dimensional automatic system AOC-5000 was used for injection of samples (GCMS-QP2010 PlusxAOC-5000). The injection of the samples was performed by HS and SPME methods. The $100 \mu \mathrm{m}$ Carboxen-PDMS fiber was used to ensure the extraction of volatile substances and semi-volatile compounds at a concentration from tenths of a ppb to tens of ppm [29]. All measurements were performed in dublicate. Results were expressed as mean \pm standard deviation (SD) and were statistically evaluated $(\mathrm{p}<0.05)$.

\section{Results and Discussion}

Initially, the qualitative characteristics of the oils used in the work were established (Table 1).

The oils taken for analysis correspond to the requirements of the given product category, they are not oxidized. Next, there was analysed the variation of PV as a function of time (Figure 3 ).

It was found that the process of forced oxidation of oils from grape seeds, walnut kernels, and corn germs were completed in about $700 \mathrm{~h}$. To establish the conditions for the rapid oxidation of oils, the influence of $\mathrm{H}_{2} \mathrm{O}_{2}$ concentration and $\mathrm{Cu}^{2+}$ ions was analysed (Figure 4).

For the accelerated oxidation process in the analysed systems, the selected optimal concentration of $\mathrm{H}_{2} \mathrm{O}_{2}$ and $\mathrm{Cu}^{2+}$ was $1 \mathrm{mmol} / \mathrm{L}$.

The most likely pathway for the breakdown of hydroperoxides was a homolytic cleavage of oxygen-oxygen bond, in which alkoxy and hydroxy radicals were produced. The alkoxy radical then undergoes the $\beta$-homolytic cleavage of the carbon-carbon bond and produces saturated or unsaturated oxo-compounds and alkyl radicals. Lipid peroxidation products were mostly low molecular weight aldehydes, ketones, alcohols and short chain hydrocarbons.

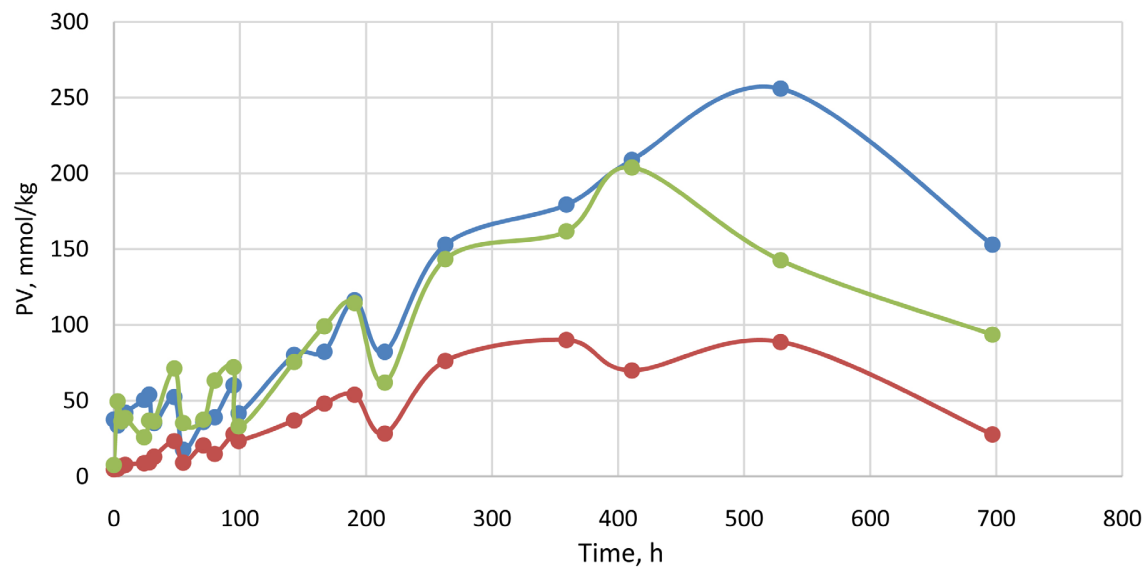

Figure 3. PV variation during the experiment: Grape seed oil $+\left[\mathrm{H}_{2} \mathrm{O}_{2}\right]=1 \mathrm{mmol} / \mathrm{L}$, $\left[\mathrm{Cu}^{2+}\right]=1 \mathrm{mmol} / \mathrm{L}$; Corn germ oil $+\left[\mathrm{H}_{2} \mathrm{O}_{2}\right]=1 \mathrm{mmol} / \mathrm{L},\left[\mathrm{Cu}^{2+}\right]=1 \mathrm{mmol} / \mathrm{L}$; Walnut oil $+\left[\mathrm{H}_{2} \mathrm{O}_{2}\right]=1 \mathrm{mmol} / \mathrm{L},\left[\mathrm{Cu}^{2+}\right]=1 \mathrm{mmol} / \mathrm{L}$. 


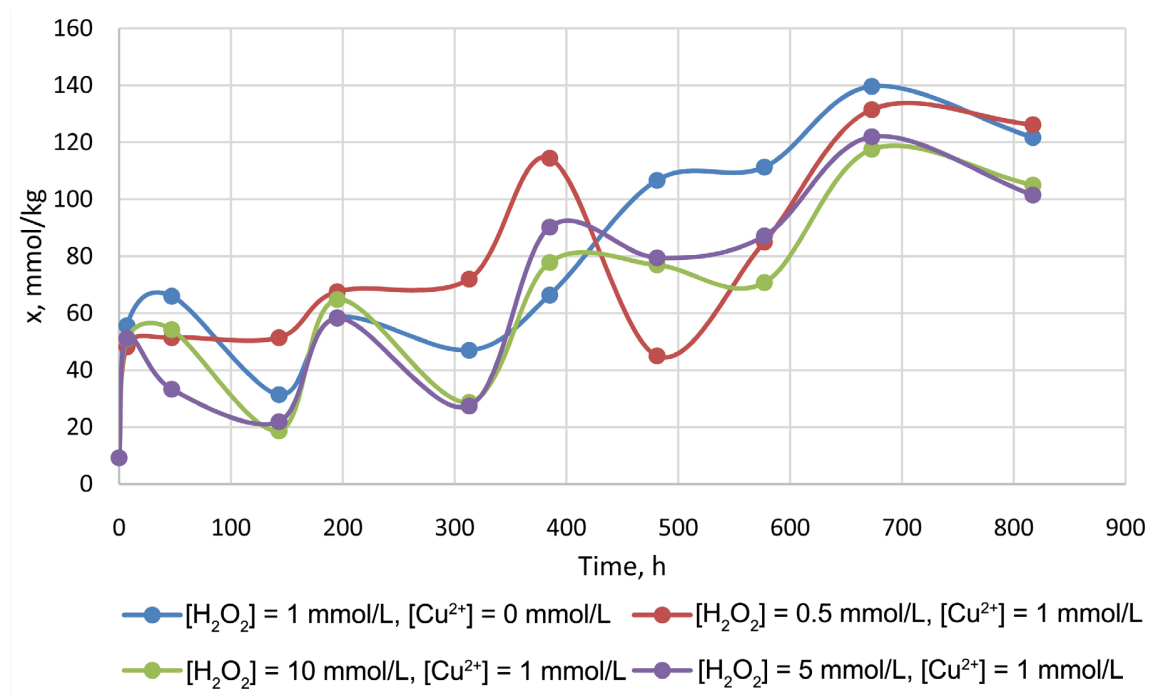

Figure 4. Oxidation of grape seed oil with different concentrations of $\mathrm{H}_{2} \mathrm{O}_{2}$ in the presence of copper ions $\left(\mathrm{Cu}^{2+}\right)$.

Table 1. Physico-chemical characteristics of oils.

\begin{tabular}{cccc}
\hline Quality index & $\begin{array}{c}\text { Grape } \\
\text { seed oil }\end{array}$ & $\begin{array}{c}\text { Corn } \\
\text { germ oil }\end{array}$ & $\begin{array}{c}\text { Walnut } \\
\text { oil }\end{array}$ \\
\hline $\begin{array}{c}\text { Acidity index, mg KOH/g oil } \\
\text { Peroxide Value, (mmol/kg oil) }\end{array}$ & 3.1 & 2.6 & 3.8 \\
Mass fraction of impurities & 9.2 & 8.8 & 9.8 \\
$\begin{array}{c}\text { (sediment mass relative to mass of sample), \% } \\
\text { Mass fraction of water and volatiles, \% }\end{array}$ & 0.20 & 0.15 & 0.25 \\
Mass fraction of unsaponifiables, \% & 0.15 & 0.10 & 0.20 \\
Relative density. & 2.0 & 1.0 & 1.2 \\
Saponification index, mg KOH/g oil & 0.925 & 0.918 & 0.922 \\
Iodine index, g $\mathrm{I}_{2} / 100$ g oil & 192 & 194 & 198 \\
\hline
\end{tabular}

Most of the hydroperoxides decomposition products were responsible for the rancid aroma of oxidized edible oil. Aliphatic carbonyl compounds had a greater influence on the aroma of the oxidized oil due to their low values. The following products of lipid oxidation in vegetable oils were quantified: hexanal, octanal and hydroxy-nonadienal (Table 2).

Oxidation of lipids, especially oils that have unsaturated fatty acids in their composition, lead to the formation of a wide range of aldehyde compounds. The formation of these compounds was monitored during the process of forced oxidation for a period of 48 hours (Figure 5).

Analysing the dynamics of hexanal formation during the oxidation of oils, we noticed that the hexanal formed following the oxidation of lipids in grape oil has is an insignificant increase within the first 6 hours, followed by a sudden increase in the next 18 hours, ending in a constant value in the last 24 hours. The 


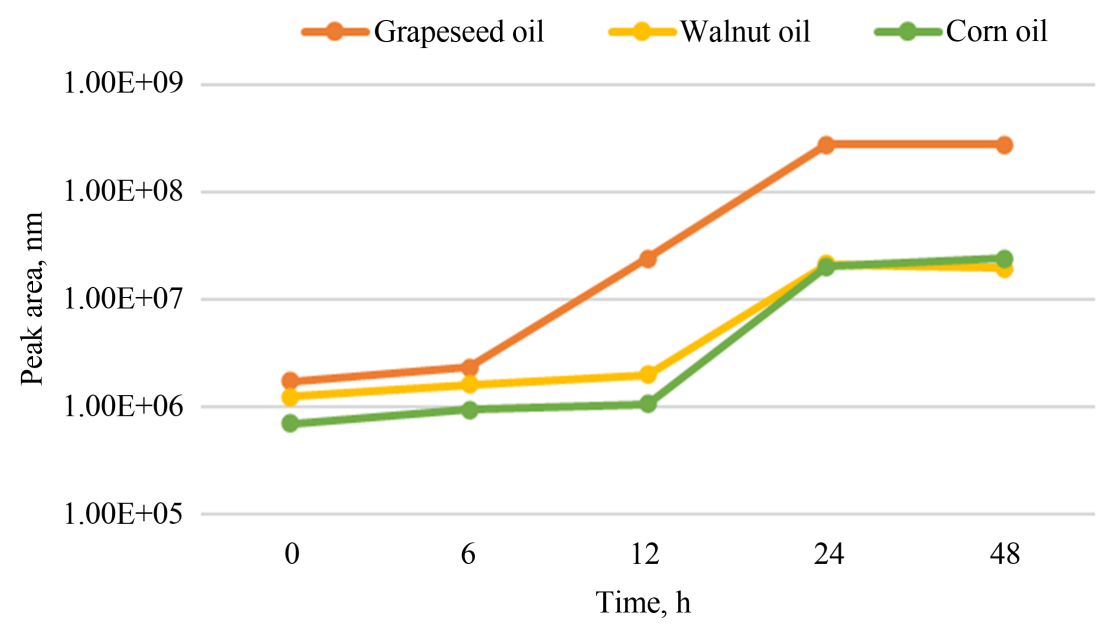

(a)

$1.00 \mathrm{E}+09 \longrightarrow$ Grapeseed oil $\longrightarrow$ Walnut oil $\longrightarrow$ Corn oil

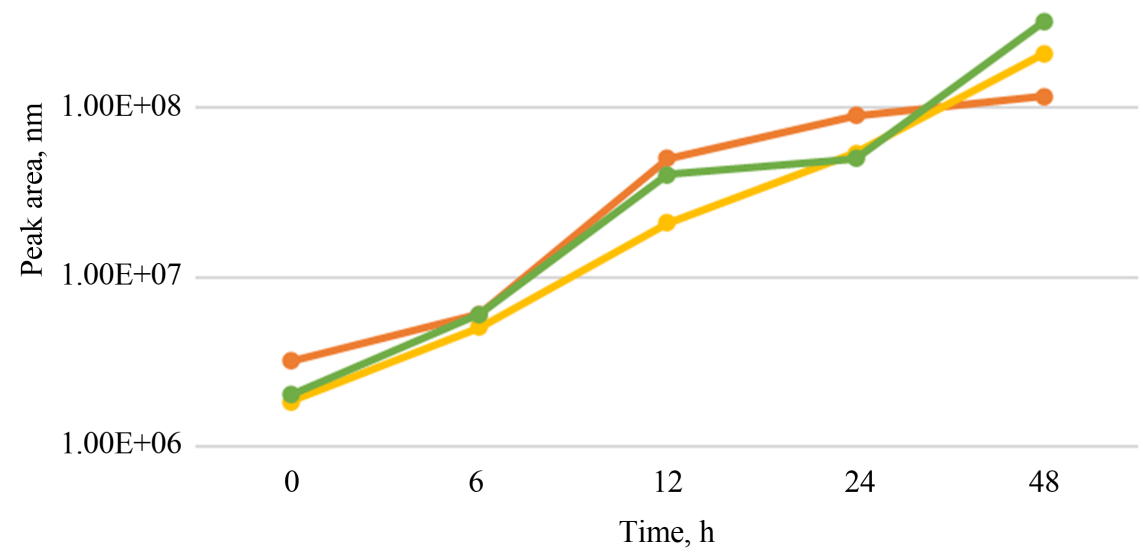

(b)

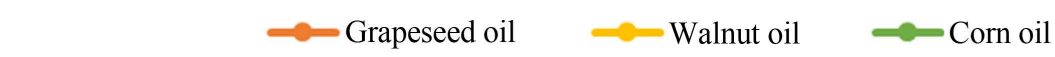

$1.00 \mathrm{E}+09$

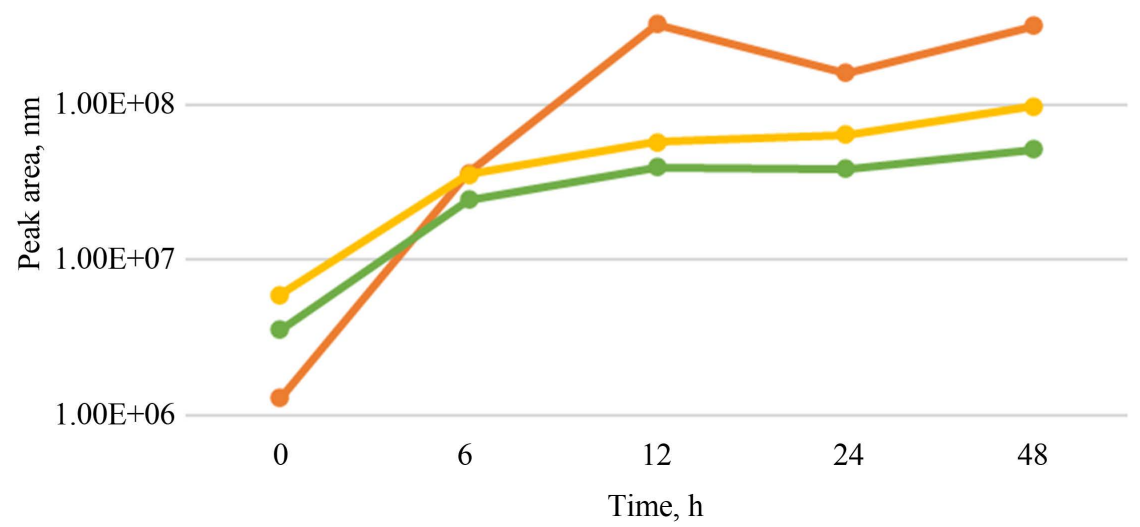

(c)

Figure 5. Dynamics of volatile compounds cumulation in oils from grape seeds, corn germ and walnut kernels: (a) Hexanal; (b) Octenal; (c) Hydroxy-nonadienal. 
Table 2. Characteristics of secondary products of lipid oxidation of vegetable oils.

\begin{tabular}{ccccc}
\hline Aldehyde & $\begin{array}{c}\text { Molar mass, } \\
\text { g/mol }\end{array}$ & $\begin{array}{c}\text { Chemical } \\
\text { formula }\end{array}$ & $\begin{array}{c}\text { Formation } \\
\text { pathway }\end{array}$ & RT \\
\hline Hexanal & 100 & $\mathrm{C}_{6} \mathrm{H}_{12} \mathrm{O}$ & Truncation & 2.89 \\
Octenal & 128 & $\mathrm{C}_{8} \mathrm{H}_{16} \mathrm{O}$ & Truncation & 4.65 \\
$\begin{array}{c}\text { Hydroxy-Nonadienal } \\
\text { (HNE) }\end{array}$ & 154 & $\mathrm{C}_{9} \mathrm{H}_{14} \mathrm{O}_{2}$ & $\begin{array}{c}\text { Truncation, } \\
\text { OH addition }\end{array}$ & 3.13 \\
\hline
\end{tabular}

dynamics for all tree oils is similar, but while the walnut and corn oils generate identical hexanal contents, in case of grape seeds oil the values are much higher, especially after 6 hours (Figure 5(a)).

At the initial stage the octenal content is a little higher in grape seed oil compared to the other samples. After 24 hours of oxidation, there was a significant increase in the amount of octenal in all three oils and the process is relatively slow down in case of grape oil in the last 24 hours (Figure 5(b)).

The hydroxy-nonadienal (HNE) was a mutagenic and cytotoxic compound, and is formed as a result of linoleic acid oxidation. The increase in HNE content in the case of lipids in grape seed oil showed a considerable evolution in the first 12 hours of exposure. After 24 hours of exposure, there was a slight decrease in HNE content, which could be explained by the subsequent degradation of aldehydes and the formation of new compounds (Figure 5(c)).

The UV spectres of the investigated oils were recorded in order to monitor the lipid oxidation process (Figure 6).

The increase in absorbance values at wavelengths at $232 / 270 \mathrm{~nm}$ demonstrated the accelerated oxidation of oils, which is expressed by the accumulation of the amount of conjugated dienes and trienes (Table 3). Thus, in the oil from grape seeds the content of $\mathrm{CD}$ increased 2.3 times, and for CT-1.6 times. In walnut oil, the respective values increased 3.6 and 1.5 times; The most pronounced changes were recorded in corn germ oil, where the content of CD increased by 4.5 and of CT by 1.5 times.

When studying the process of inhibiting the oxidation of oils, the action of a-tocopherol, n-octyl gallate, L-ascorbic acid 6-palmitate and matcha extract (green tea) was analysed. As a result of the analysis of antioxidants influence on the analized oils, it was established that the most effective oxidation inhibitors are n-octyl gallate and 6-palmitate of L-ascorbic acid. A less pronounced action was found in cases of a-tocopherol and matcha extract (green tea) (Figure 7 and Figure 8).

A maximum formation of monohydroperoxides was attested in the first 48 hours of forced oxidation. Subsequently, there was a decrease in PV (72 h), followed by slower evolution. This allure of the oxidation curve corresponded to the initiation of the process of cleavage of monohydroperoxides, confirmed by the formation of lipid oxidation secondary products, volatile compounds [30] [31]. 


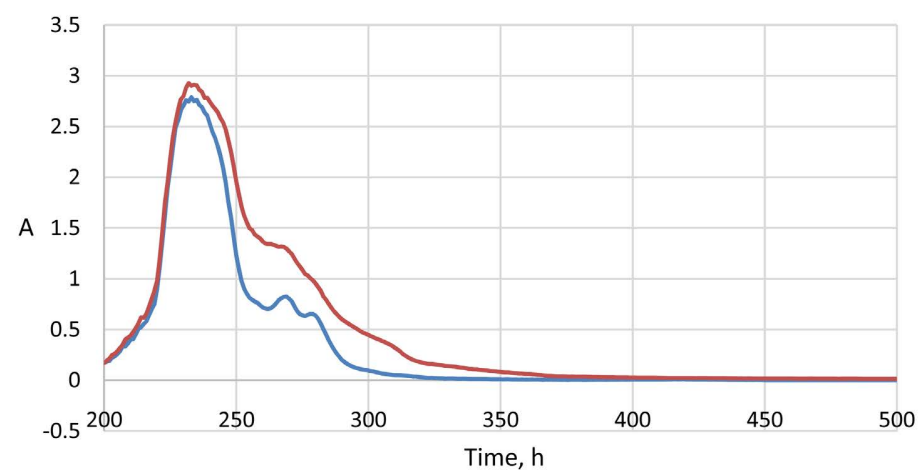

Figure 6. UV spectrum of oxidized/non-oxidized grape seed oil (solvent-hexane).

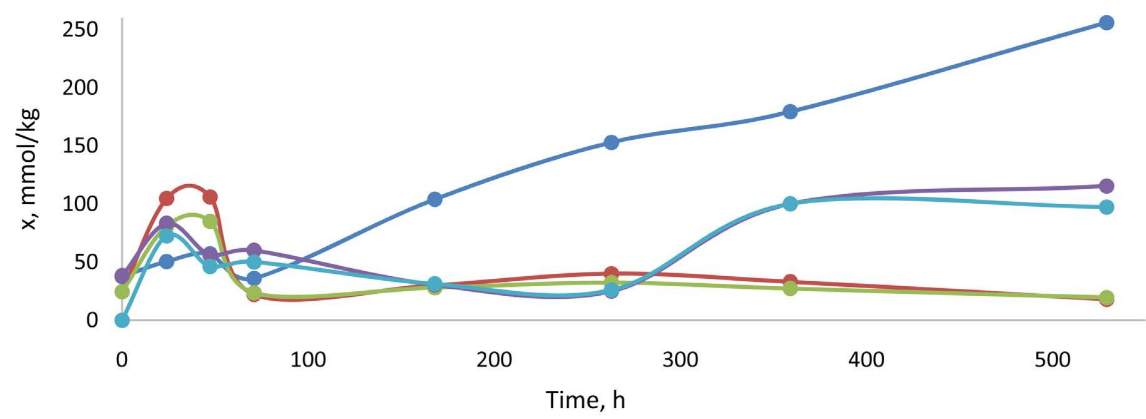

Figure 7. Oxidation (PV) of grape seed oil in the presence of $\mathrm{H}_{2} \mathrm{O}_{2}$ and antioxidants: L-ascorbic acid 6-palmitate (0.1\%); n-octyl galate (0.1\%); a -tocopherol (1\%); matcha extract (1\%). (-- oil $+\left[\mathrm{H}_{2} \mathrm{O}_{2}\right]=1 \mathrm{mmol} / \mathrm{l} ;-\cdots$ oil $+\left[\mathrm{H}_{2} \mathrm{O}_{2}\right]=1 \mathrm{mmol} / \mathrm{l}+\mathrm{LAAP} ;-\cdots$ oil + $\left[\mathrm{H}_{2} \mathrm{O}_{2}\right]=1 \mathrm{mmol} / \mathrm{l}+$ Matcha; $-\cdot-$ oil $+\left[\mathrm{H}_{2} \mathrm{O}_{2}\right]=1 \mathrm{mmol} / \mathrm{l}+\mathrm{OcGA} ; \cdots$ oil $+\left[\mathrm{H}_{2} \mathrm{O}_{2}\right]=1$ $\mathrm{mmol} / \mathrm{l}+\mathrm{a}$-tocopherol).

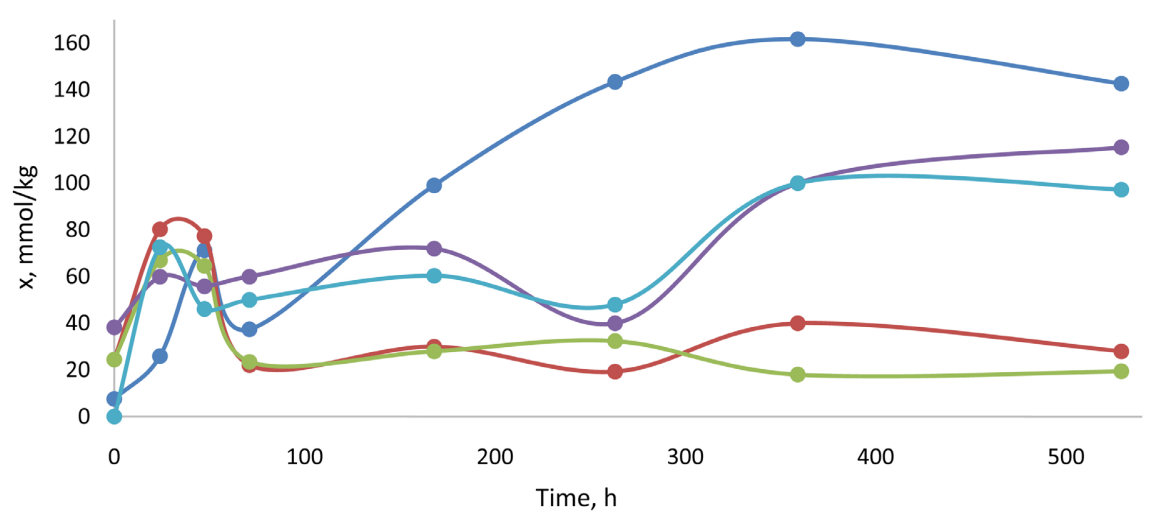

Figure 8. Oxidation (PV) of walnut kernel oil in the presence of $\mathrm{H}_{2} \mathrm{O}_{2}$ and antioxidants: L-ascorbic acid 6-palmitate (0.1\%); n-octyl galate (0.1\%); a -tocopherol (1\%); matcha extract (1\%). (-- oil $+\left[\mathrm{H}_{2} \mathrm{O}_{2}\right]=1 \mathrm{mmol} / \mathrm{L} ;-\cdots$ oil $+\left[\mathrm{H}_{2} \mathrm{O}_{2}\right]=1 \mathrm{mmol} / \mathrm{L}+\mathrm{LAAP} ;-\cdots$ oil + $\left[\mathrm{H}_{2} \mathrm{O}_{2}\right]=1 \mathrm{mmol} / \mathrm{L}+$ Matcha; -- oil $+\left[\mathrm{H}_{2} \mathrm{O}_{2}\right]=1 \mathrm{mmol} / \mathrm{L}+$ OcGA $; \cdots$ oil $+\left[\mathrm{H}_{2} \mathrm{O}_{2}\right]=1$ $\mathrm{mmol} / \mathrm{L}+\mathrm{a}$-tocopherol).

It was found that oil samples with the addition of antioxidants showed considerably lower values compared to the oxidized oil sample, which was explained by the slowdown in the formation of lipid oxidation products: peroxides and hydroperoxides. 
Table 3. Content of conjugated dienes and trienes non-oxidized and in oxidized oils from grape seeds, walnuts and maize germs*.

\begin{tabular}{|c|c|c|c|c|c|c|}
\hline \multirow{3}{*}{$\begin{array}{c}\mathrm{CD} \\
\mathrm{mmol} / \mathrm{L}\end{array}$} & \multicolumn{2}{|c|}{ Grape seed oil } & \multicolumn{2}{|c|}{ Corn germ oil } & \multicolumn{2}{|c|}{ Walnut oil } \\
\hline & initial test & 46.25 & initial test & 24.88 & initial test & 15.41 \\
\hline & oxidized sample & 104.85 & oxidized sample & 90.48 & oxidized sample & 69.98 \\
\hline $\mathrm{CT}$, & initial test & 39.80 & initial test & 8.77 & initial test & 0.18 \\
\hline $\mathrm{mmol} / \mathrm{L}$ & oxidized sample & 62.87 & oxidized sample & 13.40 & oxidized sample & 14.32 \\
\hline
\end{tabular}

*after $48 \mathrm{~h}$ of oxidation, $\left[\mathrm{H}_{2} \mathrm{O}_{2}\right]=1 \mathrm{mmol} / \mathrm{L},\left[\mathrm{Cu}^{2+}\right]=1 \mathrm{mmol} / \mathrm{L}$.

The ability of antioxidants (phenolic acids, carotenoids, vitamins) to prevent lipid oxidation was undoubtedly linked to their structural characteristics, especially the number of highly effective functional groups. -OH groups were considered substitutes with high electron donation capacity. In addition to the number, the position on the phenolic rings, as well as the intramolecular hydrogen bonds played an important role in their antioxidant performance [32].

\section{Conclusions}

Following the forced oxidation of the analized oils, the products of the oxidation reaction were identified: hexanal, octenal and hydroxinonadienal. The dynamics of the formation of lipid oxidation compounds were established over a period of 48 hours. It was found that the most intense dynamics were attested in the first 12 hours of exposure to prooxidant conditions.

$\mathrm{PV}$ varies during forced oxidation, being attested a maximum over $48 \mathrm{~h}$, followed by a significant decrease $(72 \mathrm{~h})$ and a slower subsequent ascending evolution. This allure is caused by the intense cleavage of monohydroperoxides with the formation of volatile products of lipid oxidation.

Content of CD in oxidized oils increased 2.3 - 5.5 times, and for CT-1.5 - 1.6 times. The most pronounced changes in $\mathrm{CD}$ were recorded in walnut oil (3.6 times) and corn germ oil (4.5 times).

There were evaluated the dominant volatile products of the oxidation reaction: hexanal, octenal and hydroxynonadienal. During 48 hours the curves of hexanal and hydroxy-nonadienal formation acquired a constant allure. There was a significant increase in the amount of octenal for lipids in walnut and corn oils and a lower value for grape seed oil.

The inhibitory action was demonstrated by the application of the antioxidants $\alpha$-tocopherol, L-ascorbic acid 6-palmitate, n-octyl gallate and matcha extract. It was established the effective action of L-ascorbic acid 6-palmitate and n-octyl gallate. Their optimum concentrations were $0.1 \%$. It was established that $\alpha$-tocopherol and matcha extract were less effective, the optimal concentrations were $1 \%$.

\section{Acknowledgements}

The research was funded in the framework of State Project 20.80009.500727 
"physico-chemical mechanisms of redox processes with electron transfer involved in vital, technological and environmental systems".

\section{Conflicts of Interest}

The authors declare no conflicts of interest regarding the publication of this paper.

\section{References}

[1] Choe, E. and Min, D. (2005) Chemistry and Reactions of Reactive Oxygen Species in Foods. Journal of Food Science, 70, R142-R159. https://doi.org/10.1111/j.1365-2621.2005.tb08329.x

[2] Yin, H., Xu, L. and Porter, N. (2011) Free Radical Lipid Peroxidation: Mechanisms and Analysis. Chemical Reviews, 111, 5944-5972. https://doi.org/10.1021/cr200084z

[3] Blair, I. (2001) Lipid Hydroperoxide-Mediated DNA Damage. Experimental Gerontology, 36, 1473-1481. https://doi.org/10.1016/S0531-5565(01)00133-4

[4] Maszewska, M., Florowska, A., Dłużewska, E, Wroniak, M., Marciniak-Lukasiak, K. and Żbikowska, A. (2018) Oxidative Stability of Selected Edible Oils. Molecules, 23, 1746. https://doi.org/10.3390/molecules23071746

[5] Sturza, R., Druță, R., Covaci, E., Duca, G. and Subotin, I. (2020) Mechanisms of Sunflower Oil Transforming into Forced Thermal Oxidation Processes. Journal of Engineering Science, 27, 238-251.

[6] Guillen, M. and Cabo, N. (2002) Fourier Transform Infrared Spectra Data versus Anisidine Values to Determine Oxidative Stability of Edible Oil. Food Chemistry, 77, 503-510. https://doi.org/10.1016/S0308-8146(01)00371-5

[7] Ayala, A., Muñoz, M.F. and Argüelles, S. (2014) Lipid Peroxidation: Production, Metabolism, and Signaling Mechanisms of Malondialdehyde and 4-hydroxy-2nonenal. Oxidative Medicine and Cellular Longevity, 2014, Article ID: 360438. https://doi.org/10.1155/2014/360438

[8] Repetto, M., Semprine, J. and Boveris, A. (2012) Lipid Peroxidation: Chemical Mechanism, Biological Implications and Analytical Determination. In: Catala, A., Ed., Lipid Peroxidation, IntechOpen, London, 4-30. https://doi.org/10.5772/45943

[9] Ahmed, M., Pickova, J., Ahmad, T., Liaquat, M., Farid, A. and Jahangir, M. (2016) Oxidation of Lipids in Foods. Sarhad Journal of Agriculture, 32, 230-238. https://doi.org/10.17582/journal.sja/2016.32.3.230.238

[10] Shahidi, F. and Zhong, Y. (2010) Lipid Oxidation and Improving the Oxidative Stability. Chemical Society Reviews, 39, 4067-4079. https://doi.org/10.1039/b922183m

[11] Hajeyah, A., Griffiths, W., Wang, Y., Finch, A. and O’Donnell, V. (2020) The Biosynthesis of Enzymatically Oxidized Lipids. Frontiers in Endocrinology, 11, Article ID: 591819. https://doi.org/10.3389/fendo.2020.591819

[12] Shankar, R., Shim, W.J., An, J.G. and Yim, U.H. (2015) A Practical Review on Photooxidation of Crude Oil: Laboratory Lamp Setup and Factors Affecting It. Water Research, 68, 304-315. https://doi.org/10.1016/j.watres.2014.10.012

[13] Ghnimi, S., Budilarto, E. and Kamal-Eldin, A. (2017) The New Paradigm for Lipid Oxidation and Insights to Microencapsulation of Omega-3 Fatty Acids. Comprehensive Reviews in Food Science and Food Safety, 16, 1206-1218. https://doi.org/10.1111/1541-4337.12300

[14] Poiana, M.A. (2012) Enhancing Oxidative Stability of Sunflower Oil during Con- 
vective and Microwave Heating Using Grape Seed Extract. International Journal of Molecular Sciences, 13, 9240-9259. https://doi.org/10.3390/ijms13079240

[15] Lourenço, S.C., Moldão-Martins, M. and Alves, V.D. (2019) Antioxidants of Natural Plant Origins: From Sources to Food Industry Applications. Molecules (Basel, Switzerland), 24, 4132. https://doi.org/10.3390/molecules24224132

[16] Bellili, S., Jazi, S., Nasr, S., et al. (2018) Grape Seed Oil: Chemical Composition, Biological Properties and Health Benefits.

https://www.researchgate.net/publication/325951791

[17] Garavaglia, J., Markoski, M.M., Oliveira, A. and Marcadenti, A. (2016) Grape Seed Oil Compounds: Biological and Chemical Actions for Health. Nutrition and Metabolic Insights, 9, 59-64. https://doi.org/10.4137/NMI.S32910

[18] Uzunova, G., Perifanova-Nemska, M., Stojanova, M. and Gandev, S. (2015) Chemical Composition of Walnut Oil from Fruits on Different Years Old Branches. Bulgarian Journal of Agricultural Science, 21, 494-497.

[19] Baerle, A., Tatarov, P. and Sandu, I. (2020) Polyphenols and Naphthoquinones Extraction from Walnuts Pellicula: The Impact on Kernels Quality. Journal of Engineering Science, 27, 145-153.

[20] Ni, S., Zhao, W., Zhang, Y., Gasmalla, M.A. and Yang, R. (2016) Efficient and Eco-Friendly Extraction of Corn Germ Oil Using Aqueous Ethanol Solution Assisted by Steam Explosion. Journal of Food Science and Technology, 53, 2108-2116. https://doi.org/10.1007/s13197-016-2189-9

[21] Liu, X. (2018) Progress in the Mechanism and Kinetics of Fenton Reaction. MOJ Ecology \& Environmental Sciences, 3, Article No. 00060. https://doi.org/10.15406/mojes.2018.03.00060

[22] Bastos, L.C.S. and Pereira, P.A. (2010) Influence of Heating Time and Metal Ions on the Amount of Free Fatty Acids and Formation Rates of Selected Carbonyl Compounds during the Thermal Oxidation of Canola Oil. Journal of Agricultural and Food Chemistry, 58, 12777-12783. https://doi.org/10.1021/jf1028575

[23] Botterweck, A., Verhagen, H., Goldbohm, R., Kleinjans, J., Brandt, P.V.D. and Brandt, P.V.D. (2000) Intake of Butylated Hydroxyanisole and Butylated Hydroxytoluene and Stomach Cancer Risk: Results from Analyses in the Netherlands Cohort Study. Food and Chemical Toxicology, 38, 599-605. https://doi.org/10.1016/S0278-6915(00)00042-9

[24] Carocho, M., Barreiro, M.F., Morales, P., Ferreira, I.C. and Gomez, P.M. (2014) Adding Molecules to Food, Pros and Cons: A Review on Synthetic and Natural Food Additives. Comprehensive Reviews in Food Science and Food Safety, 13, 377-399. https://doi.org/10.1111/1541-4337.12065

[25] Reboredo-Rodrigueez, P., Figueiredo-Gonzalez, M., Gonzalez-Barreiro, et al. (2017) State of the Art on Functional Virgin Olive Oils Enriched with Bioactive Compounds and Their Properties. International Journal of Molecular Sciences, 18, 668. https://doi.org/10.3390/ijms18030668

[26] Sturza, R. (2006) Modern Principles of Food Analysis. Ch.: UTM, 310 p. (In Romanian)

[27] Javidipour, I., Erinc, H., Basturk, A., et al. (2017) Oxidative Changes in Hazelnut, Olive, Soybean, and Sunflower Oils during Microwave Heating. International Journal of Food Properties, 20, 1582-1592. https://doi.org/10.1080/10942912.2016.1214963

[28] Government Decision No. 434 Regarding the Approval of the Requirements "Edible Vegetable Oils". Published 04-06-2010 in the Official Gazette No. 87-90 Art. 510. 
[29] Sturza, R., Sîrghi, C. and Vrîncean, M. (2009) Comparison of Analytical Methods Sensitivity for Samples Injection in the Detection of Compounds with Flavouring Potential of Wines. The Annals of the University Dunarea de Jos of Galati, Fascicle VI Food Technology, 34, 9-17.

[30] Piedrahita, A., Penaloza, J., Cogollo, Á. and Rojano, B. (2015) Kinetic Study of the Oxidative Degradation of Choibá Oil (Dipteryx oleifera Benth.) with Addition of Rosemary Extract (Rosmarinus officinalis L.). Food and Nutrition Sciences, 6, 466-479. https://doi.org/10.4236/fns.2015.65048

[31] Dedebas, T., Ekici, L. and Sagdic, O. (2020) Chemical Characteristics and Storage Stabilities of Different Cold-Pressed Seed Oils. Journal of Food Processing and Preservation, 45, e15107. https://doi.org/10.1111/jfpp.15107

[32] Mardani-Ghahfarokhi, A. and Farhoosh, R. (2020) Antioxidant Activity and Mechanism of Inhibitory Action of Gentisic and $\alpha$-Resorcylic Acids. Scientific Reports, 10, Article No. 19487. https://doi.org/10.1038/s41598-020-76620-2 